\title{
Performance characteristics of UV imaging instrumentation for diffusion, dissolution and release testing studies
}

Jensen, Sabrine S; Jensen, Henrik; Goodall, David M; Østergaard, Jesper

Published in:

Journal of Pharmaceutical and Biomedical Analysis

DOI:

10.1016/j.jpba.2016.08.018

Publication date:

2016

Document version

Peer reviewed version

Document license:

CC BY-NC

Citation for published version (APA):

Jensen, S. S., Jensen, H., Goodall, D. M., \& Østergaard, J. (2016). Performance characteristics of UV imaging instrumentation for diffusion, dissolution and release testing studies. Journal of Pharmaceutical and Biomedical Analysis, 131, 113-123. https://doi.org/10.1016/j.jpba.2016.08.018 
1 Performance characteristics of UV imaging instrumentation for diffusion, dissolution and

2 release testing studies

3 Sabrine S. Jensen ${ }^{\mathrm{a}, \mathrm{b}}$, Henrik Jensen ${ }^{\mathrm{a}}$, David M. Goodall ${ }^{\mathrm{c}}$ and Jesper Østergaard ${ }^{\mathrm{a}, *}$

4

5 aDepartment of Pharmacy, Faculty of Health and Medical Sciences, University of Copenhagen,

6 Universitetsparken 2, DK-2100 Copenhagen, Denmark.

7

8 bPresent address: Novo Nordisk A/S, Novo Nordisk Park, DK-2760 Måløv, Denmark.

9

10 'Paraytec Limited, York House, Outgang Lane, Osbaldwick, York, YO19 5UP, United Kingdom

13 *Correspondence: Jesper Østergaard. Department of Pharmacy, Faculty of Health and Medical

14 Sciences, University of Copenhagen, Universitetsparken 2, DK-2100 Copenhagen, Denmark. E-

15 mail: jesper.ostergaard@ sund.ku.dk, Telephone: +45 3533 6138, Fax: +45 35336001

16 This is a post-peer-review, pre-copyedit version of an article published in Journal of Pharmaceutical and

17 Biomedical Analysis.

18

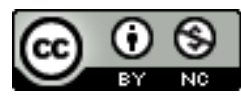

19 The final authenticated version is available online at: http://dx.doi.org/10.1016/j.jpba.2016.08.018 


\section{Abstract}

22 UV imaging is capable of providing spatially and temporally resolved absorbance measurements,

23 which is highly beneficial in drug diffusion, dissolution and release testing studies. For optimal

24 planning and design of experiments, knowledge about the capabilities and limitations of the

25 imaging system is required. The aim of this study was to characterize the performance of two

26 commercially available UV imaging systems, the D100 and SDI. Lidocaine crystals, lidocaine

27 containing solutions, and gels were applied in the practical assessment of the UV imaging

28 systems. Dissolution of lidocaine from single crystals into phosphate buffer and $0.5 \%(\mathrm{w} / \mathrm{v})$

29 agarose hydrogel at $\mathrm{pH} 7.4$ was investigated to shed light on the importance of density gradients

30 under dissolution conditions in the absence of convective flow. In addition, the resolution of the

31 UV imaging systems was assessed by the use of grids. Resolution was found to be better in the

32 vertical direction than the horizontal direction, consistent with the illumination geometry. The

33 collimating lens in the SDI imaging system was shown to provide more uniform light intensity

34 across the UV imaging area and resulted in better resolution as compared to the D100 imaging

35 system (a system without a lens). Under optimal conditions, the resolution was determined to be

$36 \quad 12.5$ and 16.7 line pairs per $\mathrm{mm}(\mathrm{lp} / \mathrm{mm})$ corresponding to line widths of $40 \mu \mathrm{m}$ and $30 \mu \mathrm{m}$ in the

37 horizontal and vertical direction, respectively. Overall, the performance of the UV imaging

38 systems was shown mainly to depend on collimation of light, the light path, the positioning of

39 the object relative to the line of 100 micron fibres which forms the light source, and the distance

40 of the object from the sensor surface. 
42 Keywords: Dissolution imaging; Dissolution testing; Instrument performance; Spatial

43 resolution; UV imaging

44 Abbreviations: API, active pharmaceutical ingredient; CARS, coherent anti-Stokes Raman

45 Scattering Microscopy; CMOS, Complementary metal oxide semiconductor; FTIR, Fourier

46 transform infrared; LOD, Limit of detection; MRI, magnetic resonance imaging; TDA, Taylor

47 dispersion analysis.

49 1. Introduction

50 Dissolution and release testing is conducted for various purposes in the pharmaceutical industry

51 e.g., to guide the drug development process, in quality control, and as biowaivers [1]. In the early

52 phases of drug development, miniaturized or micro-scale techniques requiring low-milligram

53 quantities of the active pharmaceutical ingredient (API) or formulation are of particular value [2-

54 4]. Many dissolution and release testing methods are invasive methods and involve bulk solution

55 concentration measurements by the withdrawal of test samples, which may disturb the

56 subsequent release. In addition, the withdrawal of samples may also lead to delayed responses,

57 due to the need for accumulation of the API in solution. Especially, in case of fast dissolution

58 and release kinetics real-time analysis is advantageous. Better understanding of the dissolution or

59 release behavior of an API or formulation may be attained using imaging techniques providing

60 spatially, spectrally, and/or temporally resolved information. Imaging techniques used in

61 pharmaceutical sciences for investigating drug dissolution and release processes include

62 magnetic resonance imaging (MRI) [5-8], Fourier transform infrared (FTIR) imaging [4, 9-11],

63 coherent anti-Stokes Raman Scattering Microscopy (CARS) imaging [12], fluorescence imaging 
$64[13,14]$, and UV imaging [15,16]. UV imaging is compatible with a small scale format and has

65 attracted attention as it offers insights into dissolution and release processes of drugs [17-27].

66 However, limited data are available regarding system performance of the commercially available

67 UV imaging instrumentation. The current study was prompted by observations made during UV

68 imaging experiments in our lab, and an associated wish to understand better the performance

69 characteristics of the instrumentation, since this knowledge would be useful in the design,

70 planning, and execution of future experiments. The purpose of the present study was to

71 characterize two embodiments of a commercially-available UV imaging system in terms of

72 analytical performance, including spatial resolution, linearity and noise. The instruments subject

73 to study were an SDI (Sirius-Analytical, Forest Row, UK) and a D100 (Paraytec Ltd, York, UK)

74 imaging system.

\section{Experimental}

2.1 Materials and sample preparations

79 and sodium dihydrogenphosphate monohydrate were obtained from Merck (Darmstadt,

80 Germany). Lidocaine (Ph Eur (European Pharmacopoeia) 6th ed.) was obtained from Unikem

81 (Copenhagen, Denmark). Lidocaine crystals were prepared as described previously [16].

82 A $0.067 \mathrm{M}$ phosphate buffered solution with an ionic strength of $0.15 \mathrm{M}$ was prepared as

83 follows. A weighed amount of sodium dihydrogenphosphate monohydrate (9.25 g) was

84 transferred to a $1000 \mathrm{ml}$ volumetric flask to which was then added de-ionized water to the neck 
85 of the volumetric flask. The mixture was stirred at room temperature until the substance was

86 dissolved, then the $\mathrm{pH}$ adjusted to 7.40 by adding $5 \mathrm{M} \mathrm{NaOH}$.

87 For preparing the agarose hydrogels, a weighed amount of agarose powder, corresponding to

$880.5 \%(\mathrm{w} / \mathrm{v})$, was suspended in phosphate buffer at $\mathrm{pH} 7.4$ followed by heating of the agarose

89 suspensions to $98^{\circ} \mathrm{C}$ for approximately $20 \mathrm{~min}$ to dissolve the agarose. The agarose solution

90 (approximately $310 \mu \mathrm{l})$ was transferred to a quartz cell $(8.0 \mathrm{~mm} \times 1.0 \mathrm{~mm} \times 38 \mathrm{~mm}(\mathrm{H} \times \mathrm{W} \times$

91 L)) (Starna Scientific Ltd, Hainault Essex, UK), and the lid of the cell placed on top of the

92 agarose solution. Each quartz cell containing the agarose solution (the pre-gel) was left at room

93 temperature for at least $0.5 \mathrm{~h}$ to ensure complete gelation of the agarose matrix.

94 The grids used for estimation of the resolution consisted of a black image made of silver halides

95 (5 $\mu \mathrm{m}$ print layer thickness) coated on one side of a plastic base of polyester (180 $\mu \mathrm{m}$ thickness).

96 The grids were produced under conditions of $21^{\circ} \mathrm{C}$ at $50 \%$ humidity (JD Photo-Tools, Oldham,

97 UK). The grids were drawn in AutoCAD software (Autodesk Inc., San Rafael, CA, USA). The

98 width of the lines and the distance between the lines were identical and varied in the range 10 -

$99100 \mu \mathrm{m}$ in $10 \mu \mathrm{m}$ increments and then in $20 \mu \mathrm{m}$ increments in the 100 to $400 \mu \mathrm{m}$ range.

100

1012.2 Instrumentation

102 The two imaging systems investigated, both utilizing ActiPix technology, were a D100 (Paraytec

103 Ltd., York, UK) and an SDI (Sirius-Analytical, Forest Row UK). In terms of optical design

$104[28,29]$, the Sirius SDI has improvements relative to the D100 through incorporating a lens for

105 collimating the light in the direction parallel to the line of $90 \times 100 \mu \mathrm{m}$ optical fibres which 
106 provide the $9 \mathrm{~mm} \times 100 \mu \mathrm{m}$ illumination source. The UV imaging systems are shown in

107 Supplementary data Fig. S.1. The active pixel CMOS sensors have a total detection area of $9 \mathrm{~mm}$

$108 \times 7 \mathrm{~mm}$ consisting of $1280 \times 1024$ pixels with a size of $7 \mu \mathrm{m} \times 7 \mu \mathrm{m}$. Band pass filters with a

109 band width of $10 \mathrm{~nm}$ were sourced from various manufacturers. Images were recorded and

110 analyzed using ActiPix D100 software version 1.4 (Paraytec Ltd.). Images were recorded with a

111 rate of 0.2 images per second, and the integration time was $10 \mathrm{~ms}$. Pixel intensities were

112 converted into absorbance using the ActiPix D100 software.

113

$114 \quad 2.3$ Methods and measurements

$115 \quad$ 2.3.1 Linearity

116 Calibration curves of lidocaine in phosphate buffered solution at $\mathrm{pH} 7.4$ in a concentration range

117 of $5 \times 10^{-6}-1 \times 10^{-2} \mathrm{M}$ were constructed. Absorbance values of lidocaine solutions were

118 measured in quartz cells with light paths of 1 and $4 \mathrm{~mm}$ at a wavelength of 214 or $254 \mathrm{~nm}$ using

119 the SDI UV imaging system. The results were compared to results obtained using a conventional

120 spectrophotometer (Shimadzu UV-1700, Shimadzu, Kyoto, Japan) and quartz cuvettes with a 10

121 mm light path.

122

$123 \quad$ 2.3.2 Noise

124 Assessment of noise was made from the data recorded while preparing the lidocaine calibration 125 curves in phosphate buffered solution at pH 7.4 using the Sirius SDI imaging system. Lidocaine 
126 solutions were flowed through the flow cell with an ActiPix flow-through type dissolution

127 cartridge CADISS-3 (Paraytec Ltd.) at a flow rate of $1.0 \mathrm{ml} / \mathrm{min}$. The pixels were binned $10 \times 1$

$128(\mathrm{x} \times \mathrm{y})$, the images were obtained at a rate of 1.15 frames per second, and the absorbance was

129 read from 5 effective pixel units positioned at different positions in the imaging area.

$131 \quad$ 2.3.3 Resolution measurement using grids

132 Resolution measurements were carried out by placing the grid in an empty $1 \mathrm{~mm}$ quartz cell (8.0

$133 \mathrm{~mm} \times 1.0 \mathrm{~mm} \times 36.0 \mathrm{~mm}(\mathrm{H} \times \mathrm{W} \times \mathrm{L}))$ or a $1 \mathrm{~mm}$ quartz cell filled with $0.067 \mathrm{M}$ phosphate

134 buffered solution, $\mathrm{pH} 7.40$, or $0.5 \%(\mathrm{w} / \mathrm{v})$ agarose gel, $\mathrm{pH} 7.40$. In these experiments, the grid is

135 located $1.2 \mathrm{~mm}$ above the cover slip of the sensor surface. Additional measurements were carried

136 out where the grid was placed directly on the cover slip of the sensor surface. Measurements

137 were performed at $610 \mathrm{~nm}$ with the pixels binned $1 \times 1$ and $4 \times 4$ using the D100 and the SDI

138 imaging systems. The resolution measured by the grids is given as the maximum number of line

139 pairs per $\mathrm{mm}(\mathrm{lp} / \mathrm{mm})$ [30] for which the correct number of line pairs can be resolved by eye.

$141 \quad$ 2.3.4 Resolution measured using lidocaine crystals

142 Lidocaine crystals were arranged in a quartz cuvette and imaged at 254 and $610 \mathrm{~nm}$ with pixel

143 binning of $1 \times 1$ or $4 \times 4$ using the SDI imaging system. The dimensions of the crystals were

144 furthermore measured using a Dino-Lite Premier Digital microscope (AM-7013MZT, AnMo

145 Electronics Corporation, Hsinchu, Taiwan) with a magnification of $\times 50$. 
$147 \quad$ 2.3.5 Density gradients

148 Dissolution of lidocaine from single crystals was investigated in $0.067 \mathrm{M}$ phosphate buffer, $\mathrm{pH}$

149 7.4, and $0.5 \%$ w/v agarose gel, $\mathrm{pH} 7.4$, in $1 \mathrm{~mm}$ quartz cells (see section 2.3.3) at $254 \mathrm{~nm}$ using

150 the SDI imaging system with pixels binned $4 \times 4$. To secure lidocaine single crystals during their

151 dissolution into $0.067 \mathrm{M}$ phosphate buffered solution, $\mathrm{pH} 7.4$, they were fixed at one end with

152 Bantex Tack-all removable adhesive (Bantex A/S, Lynge, Denmark) in the quartz cell.

154 2.3.6 Lidocaine diffusion in hydrogel

155 Diffusion of lidocaine from a $0.5 \%$ agarose gel at $\mathrm{pH} 7.4$ loaded with $1 \mathrm{mM}$ lidocaine into a

156 blank 0.5\% agarose gel, $\mathrm{pH} 7.4$, was studied using the SDI and D100 UV imaging systems in 1

157 mm quartz cells (see section 2.1). The D100 system was applied initially using the standard

158 setting and subsequently with the illumination source, the line end of the round-to-line fibre optic

159 cable, rotated by $90^{\circ}$ (cf. section 2.2 for details on the line configuration of the fibre optic

160 bundle). The imaging was performed at a wavelength of $254 \mathrm{~nm}$.

161 The diffusion coefficient $(D)$ of lidocaine in the hydrogel matrix was determined from the UV

162 absorbance maps as a function of time by applying the following derivation of Fick's second law

$163[21,31]:$

$164 \quad \frac{C(x, t)}{C_{0}}=\frac{1}{2}-\frac{1}{2} \operatorname{erf}\left(\frac{x-x_{0}}{2 \sqrt{t \cdot D}}\right)$ 
165 where $C_{(x, t)}$ is the measured concentration as a function of distance and time, $C_{0}$ is the initial 166 analyte concentration in the donor gel, erf is the error function, $x_{0}$ is the position of the interface

167 between the gel phases and $x$ is the distance from the gel-gel interface and $t$ is the time. Eq. 1 is 168 applicable for one-dimensional diffusion. In Eq. 1, the measured absorbance was used instead of 169 the concentration, because the measured absorbance values were within the linear range 170 according to Lambert Beer's law.

172 2.3.7 Diffusion coefficient of lidocaine in phosphate buffered solution

173 The diffusion coefficient of lidocaine in phosphate buffer at $\mathrm{pH} 7.4$ was determined by Taylor 174 dispersion analysis (TDA) at $25{ }^{\circ} \mathrm{C}$ as previously described by Ye et al. [32]. A sample of $5.0 \times$

$17510^{-3} \mathrm{M}$ lidocaine in $0.067 \mathrm{M}$ phosphate buffered solution was introduced into a fused silica 176 capillary $(75 \mu \mathrm{m}(\mathrm{id}) \times 200 \mu \mathrm{m}(\mathrm{od}))$ by pressure $(50 \mathrm{mbar})$ for $7 \mathrm{~s}$. The sample was forced

177 through the capillary at a constant rate, and the broadening of the lidocaine sample plug due to 178 convective diffusion was detected through two windows in the capillary by UV area imaging at $179214 \mathrm{~nm}$. The diffusion coefficient of lidocaine was determined from the peak appearance times 180 and the variances of the Gaussian shaped peaks as described by Ye et al. [32].

\section{3. Results and discussion}

183 3.1 Performance characteristics of the UV imaging systems 
184 The D100 UV imaging system was initially designed for use as detector in separation science

185 [29,33-36]. Subsequently, applications in drug dissolution and release testing have emerged [20].

186 Fig. 1 shows a schematic representation of the basic UV imaging setup for monitoring surface

187 dissolution. The prototype systems have been described in some detail [29,34-36], and

188 methodology for capillary imaging with the D100 is covered elsewhere [28]. The key

189 components include a pulsed Xe lamp emitting light in the wavelength range 190 to $1100 \mathrm{~nm}$,

$19012.5 \mathrm{~mm}$ diameter band-pass filters with $10 \mathrm{~nm}$ bandwidth (22 nm at $214 \mathrm{~nm})$ for wavelength

191 selection, and a round-to-line fiber optical bundle, where the fibers are arranged in a line

192 configuration at the end, presenting the light to the measurement zone (an array of 90 fibers with

193 a diameter of $100 \mu \mathrm{m})$. The light is transmitted through the sample and reaches the detector part

194 consisting of a cover slip, a layer of UV down-converting phosphor and an IBIS4

195 complementary metal oxide semiconductor (CMOS) sensor (Cypress, Mechelen, Belgium) with

$1961280 \times 1024$ pixels with dimensions of $7 \mu \mathrm{m} \times 7 \mu \mathrm{m}$ (total imaging area $9 \times 7 \mathrm{~mm}^{2}$ ). The CMOS

197 sensor is light sensitive in the range 400 to $1000 \mathrm{~nm}$, thus the role of a UV down-converting

198 phosphor layer $\left(\mathrm{Gd}_{2} \mathrm{O}_{2} \mathrm{~S}: \mathrm{Tb}\right)$ is to convert light in the UV wavelength range $(190-290 \mathrm{~nm})$ to

199 the visible wavelength range (a line emission spectrum emitting at several wavelengths with the

200 most prominent emission at $540 \mathrm{~nm}$ [37]), where the sensor is sensitive. The principles of UV

201 converting phosphors are described elsewhere $[38,39]$. The associated electronics and software

202 allow for the construction of images, which may be read in intensity or absorbance mode.

203 The UV imaging systems allow real-time monitoring of the experiments subject to study. Light

204 intensity maps are displayed on a PC using the ActiPix software, and illustrated in Fig. 2 for the

205 D100 and the Sirius SDI. With the D100 (Fig. 2A), the intensity distribution in the xy plane

206 showing a maximum at $\mathrm{y} \sim 3 \mathrm{~mm}$ for all $\mathrm{x}$ is consistent with the line of fibres positioned above 
207 the imager at $\mathrm{y} \sim 3 \mathrm{~mm}$ and aligned in the $\mathrm{x}$ direction. In the SDI system (Fig. 2B), the light 208 intensity is more uniform across the imaging area, particularly in y direction; however, the light

209 intensity is comparatively lower. The relatively uniform light intensity across the imaging area is

210 related to the incorporation of a collimating lens in the SDI system, leading to a change in how

211 the light is presented to the sample and sensor surface (cf. Fig. 3). The collimating lens

212 constitutes the major difference between the two systems. The presentation of the light to the 213 sample cell and sensor surface is of importance. This is further corroborated by measuring the

214 apparent height from the lower to the upper surface of the flow cell (Fig. 1) to quantify the 215 shadowing effect (Fig. 3). The directly measured height for the open section of this machined 216 part was $3.44 \mathrm{~mm}$. Apparent height values of $4.12 \mathrm{~mm}$ and $3.46 \mathrm{~mm}$ were reported from the 217 ActiPix software from the images of the cell insert taken with the D100 and the Sirius SDI, 218 respectively. The latter value is in good agreement with the true height, consistent with the light 219 being fairly well collimated. The former value accords with a shadowing effect, in which light at 220 any angle which hits the lower or upper surfaces of the insert is obscured.

221 When using the D100, this may contribute to the difficulties in calculating dissolution rates from 222 UV images and matching those to dissolution rates obtained from the collected effluent, as was 223 the case for paracetamol dissolution studies [20,40]. Also, so called surface concentrations 224 obtained using a D100 UV imaging system should be considered as concentration estimates, 225 since the line of fibres is centred at a y distance greater than the location of the lower surface of 226 the cell insert, the first unobscured ray to reach the imager is transmitted through a layer of fluid 227 significantly elevated from the surface. 
230 UV imaging relies on the molecular absorbance of light. Pixel intensities are converted into 231 absorbance using the instrument software according to:

$232 A=\log \left(\frac{I_{r e f}-I_{d}}{I_{s i g}-I_{d}}\right)$

233 where $I_{d}, I_{\text {ref }}$ and $I_{\text {sig }}$ are the ADC counts (a measure of intensity which will be referred to as

234 pixel intensity in the following) due to the dark current (electronic noise measured with the lamp 235 turned off), pixel intensity measured with the phosphate buffer (solvent) in the cell (reference 236 signal), and pixel intensity measured during the experiment, respectively. The conversion into 237 absorbance eliminates (to a large extent) the effects of non-uniformity of light intensity across 238 the imaging surface as previously shown [41]. However, imaging artifacts have been observed, 239 mainly in the edges of the images, which are related to low light intensity in this part of the 240 imaging area (this has primarily been observed when using the D100 system). Examples of UV 241 images showing such artifacts can be found in $[42,43]$. These imaging artifacts are most likely 242 due to drift in the output of the light source over time, which will have the most predominant 243 effect, when the light intensity is low. Drift in light intensity will mainly be an issue in release 244 and diffusion studies, such as described in $[42,43]$, where the self-referencing options of the 245 software used in flow-through type dissolution studies cannot be applied.

246 The absorbance measured by UV imaging may be converted into concentration using Lambert 247 Beer's law by the aid of a calibration curve. Deviations from Lambert Beer's law may occur due 248 to a number of effects: the use of polychromatic rather than monochromatic radiation; the 
presence of stray light; refractive index changes; close proximity of the absorbing molecules

250 affecting their charge distribution and thereby altering their absorptivity; the molecules taking

251 part in reactions (such as self-association and chemical degradation) and scattering effects due to

252 particles [44-46]. The linearity of the system should therefore be investigated prior to dissolution

253 and release testing experiments. Calibration curves obtained using the SDI imaging system for

254 lidocaine solutions in quartz cells with light paths of 1 and $4 \mathrm{~mm}$, and in a conventional

255 spectrophotometer with a light path of $10 \mathrm{~mm}$ are shown in Fig. 4. The use of different

256 instrumentation for absorbance measurements leads to the following apparent molar absorption

257 coefficients $\left(\varepsilon_{254}\right)$ at $254 \mathrm{~nm}: 6.2 \times 10^{2} \mathrm{M}^{-1} \mathrm{~cm}^{-1}, 6.5 \times 10^{2} \mathrm{M}^{-1} \mathrm{~cm}^{-1}$, and $4.0 \times 10^{2} \mathrm{M}^{-1} \mathrm{~cm}^{-1}$

$258(\mathrm{RSD}<4 \% ; \mathrm{n}=3)$, when the light paths were $1 \mathrm{~mm}(\mathrm{SDI}), 4 \mathrm{~mm}(\mathrm{SDI})$, and $10 \mathrm{~mm}$ (double

259 beam spectrophotometer), respectively. At $214 \mathrm{~nm}$ the following apparent molar absorption

260 coefficients $\left(\varepsilon_{214}\right)$ were obtained: $4.7 \times 10^{3} \mathrm{M}^{-1} \mathrm{~cm}^{-1}, 4.1 \times 10^{3} \mathrm{M}^{-1} \mathrm{~cm}^{-1}$ and $11.2 \times 10^{3} \mathrm{M}^{-1} \mathrm{~cm}^{-1}$

$261(\mathrm{RSD} \leq 7 \% ; \mathrm{n}=3)$, when the light paths were 1,4 , and $10 \mathrm{~mm}$, respectively. The calibration

262 curves were constructed by averaging the absorbance values over a large part of the imaging area

263 from absorbance readings over at least $1 \mathrm{~min}$, in order to minimize the uncertainty and get the

264 best estimate of the molar absorption coefficients. Fig. 4 shows that the calibration curves

265 obtained by UV imaging bend off at absorbance values around 0.5 and 1 at light paths of 1 and 4

$266 \mathrm{~mm}$, respectively, while the calibration curve was linear up to an absorbance of approximately 2

267 at a light path of $10 \mathrm{~mm}$ using the conventional spectrophotometer. We have previously reported

268 a $\varepsilon_{254}$ of $4.36 \times 10^{2} \mathrm{M}^{-1} \mathrm{~cm}^{-1}$ for lidocaine in the same phosphate buffer using a $3 \mathrm{~mm}$ light path

269 quartz cell and an SDI300 imaging system (using a D100 sensor head configuration) [16]. The

270 results show the importance of using a calibration curve that is constructed in the quartz cell, and

271 using the band pass filter as well as the same system as the actual measurements will be 
272 performed on. The performance of the total system is dependent on the light path, collimation of

273 light and band pass width as well as the performance of the detector.

274 During the absorbance measurements of the standard solutions for construction of the calibration

275 curves, the noise of the SDI imaging system was assessed. The peak to peak noise was estimated

276 to be $\sim 18$ and $\sim 35 \mathrm{mAU}$ at 214 and $254 \mathrm{~nm}$, respectively (Supplementary data Fig. S2; quartz

277 cell with $4 \mathrm{~mm}$ light path). A higher light intensity at $214 \mathrm{~nm}$ is the reason for the lower noise

278 level at $214 \mathrm{~nm}$ as compared to $254 \mathrm{~nm}$. From the data shown in Supplementary data Fig. S2 and

279 the slope of the calibration curve, the LOD $(\mathrm{S} / \mathrm{N}=3)$ for lidocaine in phosphate buffer was

280 calculated to $3.3 \times 10^{-5} \mathrm{M}$ and $4.0 \times 10^{-4} \mathrm{M}$ at 214 and $254 \mathrm{~nm}$, respectively. These LOD values

281 are based on readings with individual effective pixels $(10 \times 1$ binning), which together with the

282 low molar absorption coefficients provide the reason for the relatively high LODs.

283 Fig. 5 shows detector response (pixel intensity) as a function of wavelength for the band-pass

284 filters available in our lab using the SDI imaging instrument. The pixel intensities were read

285 from the same area $\left(5.60 \times 4.76 \mathrm{~mm}^{2}\right)$ in all experiments to limit effects of the non-uniform

286 intensity across the image surface. The detector response depends on the lamp intensity,

287 transmittance of the band-pass filters, and efficiency of the UV down-converting phosphor in the

288 UV range, and how these parameters vary as a function of the wavelength. Fig. 5 reveals a low

289 pixel intensity/detector response in the wavelength interval 300 - $350 \mathrm{~nm}$ making UV imaging

290 difficult in this range. The relatively poor performance in the range $300-350 \mathrm{~nm}$ results from the

291 combination of a relatively low light output from the Xe lamp and poor efficiency of the UV

292 down-converting phosphor $\left(\mathrm{Gd}_{2} \mathrm{O}_{2} \mathrm{~S}: \mathrm{Tb}\right.$ [37]). These issues have also been described for a CCD

293 detector utilizing UV down-converting phosphors [38,39]. Fig. 5 highlights another interesting 
294 feature requiring attention in, namely that the transmission efficiency of the individual band pass 295 filters vary.

297 3.1.2 Resolution of the UV imaging systems

298 Previous studies in our lab have indicated that the resolution of the UV imaging system is 299 different in the horizontal (x) and vertical (y) direction. In the following, studies were performed 300 to shed light on the resolution of the UV imaging systems. The resolution was assessed using 301 grids with line pairs (a black and transparent line constitute a line pair) having widths between 10 302 and $400 \mu \mathrm{m}$. The line pair-width intervals were $10 \mu \mathrm{m}$ below $100 \mu \mathrm{m}$, and $20 \mu \mathrm{m}$ above $100 \mu \mathrm{m}$.

303 The measurements were performed in the visible wavelength range, where the film is transparent 304 and the grid lines absorb the light. Fig. 6 shows the absorbance maps of a grid with a line width 305 of $100 \mu \mathrm{m}$ placed on the cover slip of the sensor surface or in a quartz cell, leading to a position 306 of the grid $1.2 \mathrm{~mm}$ above the cover slip of the sensor surface for the D100 and SDI imaging 307 system due to the thickness of the quartz wall. High and low absorbance values are indicated by 308 red and blue coloring, respectively, in the absorbance maps. A clear difference in the 309 performance of the imaging systems in the $\mathrm{x}$ - and $\mathrm{y}$-direction is seen from these images. This is 310 due to the light coming from the fiber optic bundle with a line configuration above the CMOS 311 chip (Fig. 3). An improved resolution is observed when the grid-lines are placed parallel to the 312 light source line. In Table 1, the estimated resolution of the imaging systems is given as

313 maximum line pairs per $\mathrm{mm}(\mathrm{lp} / \mathrm{mm})$. In empty quartz cells and quartz cells filled with phosphate 314 buffered solution or $0.5 \%(\mathrm{w} / \mathrm{v})$ agarose hydrogel at $\mathrm{pH} 7.4$, the resolution of the D100 and SDI 315 imaging systems with pixels binned $4 \times 4$ (nominal resolution of $28 \mu \mathrm{m}$ ) were determined to be 
1.7 and $2.5 \mathrm{lp} / \mathrm{mm}$, respectively, in the $\mathrm{x}$-direction and 10 and $12.5 \mathrm{lp} / \mathrm{mm}$, respectively, in the $\mathrm{y}$ -

317 direction. A resolution of $12.5 \mathrm{lp} / \mathrm{mm}$ indicates that the system is able to separate and measure

318 lines with a width of $40 \mu \mathrm{m}$. According to Table 1, the resolution is substantially better when the

319 grid is placed directly on the cover slip of the sensor surface as compared to on the quartz cell.

320 Thus, the resolution depends on the position of the object above the cover slip of the sensor

321 surface, and it decreases as the object gets closer to the light emission slit. This can be seen as a

322 result of a shadowing / optical lever effect (Fig. 3 and section 3.1). The pixel-binning $(1 \times 1$

323 versus $4 \times 4$ ) does not seem to have a large effect on the resolution. The results show that the

324 minimum resolvable feature size is greater than the size of the effective pixel. This is primarily

325 due to the optical lever effect combining the width of the light source $(100 \mu \mathrm{m}$ diameter for the

326 optical fibres) and the relatively short $(9 \mathrm{~mm})$ distance from fibre output to sensor surface. By

327 comparison with the D100, Table 1 highlights an improved resolution for the SDI due to

328 movement of the source to a greater distance away from the sensor surface and incorporation of a

329 collimating lens. The highest resolution was observed using the SDI system without any pixel

330 binning, when the grid was placed on the cover slip of the sensor surface, and was measured to

331 be 12.5 and $16.7 \mathrm{lp} / \mathrm{mm}$ (corresponding to line widths of 40 and $30 \mu \mathrm{m}$ ) in the $\mathrm{x}$ - and $\mathrm{y}$-direction,

332 respectively.

333 Since the grids were not transparent in the UV range, and because the resolution also depends on

334 the level of contrast available, an alternative approach was developed to estimate resolution in

335 this spectral region which is of primary interest for dissolution studies. The dissolution of

336 lidocaine from selected single crystals into stagnant phosphate buffered solution has earlier been

337 investigated by UV imaging at $254 \mathrm{~nm}$ [16]. In order to show how the spatial resolution of the

338 two imaging systems influences the size and shape of the imaged objects, such lidocaine crystals 
were imaged at wavelengths of 254 and $610 \mathrm{~nm}$ in the absence of dissolution medium.

340 Microscope photographs and UV images of selected lidocaine crystals are shown in Fig. 7A and

341 B. Both Fig. 6 and 7 show that the resolution of the imaging systems is better in the y-direction

342 as compared to in the $\mathrm{x}$-direction. In the current project, the width of the lidocaine crystal was

343 measured at a selected position under the microscope to be $185.6 \mu \mathrm{m}$ (Fig. 7A). The UV-Vis

344 systems were able to identify and detect lidocaine crystals, but the width of the crystal placed

345 parallel or perpendicular to the emission slit was measured to 230 or $480 \mu \mathrm{m}$, respectively, by

346 the SDI system with pixels binned $4 \times 4$ at $254 \mathrm{~nm}$ (Figs. 7B and C). It is evident that UV-Vis

347 imaging overestimates the thickness of the lidocaine crystal; this is due to the optical lever and

348 shadowing effects with the object (Fig. 7B).

349 Absorbance - distance profiles were constructed from the absorbance maps of the lidocaine

350 crystals, and the resolution of the imaging system was determined based on the sharpness of the

351 interface, as previously described by Chan et al. [47], by measuring the distance over which the

352 normalized absorbance fell from 95 to $5 \%$ of the maximum value. The normalized absorbance -

353 distance profiles of the selected lidocaine crystals are shown in Fig. 7D. Based on this procedure,

354 the resolution of the SDI imaging system at $254 \mathrm{~nm}$ with the pixels binned $4 \times 4$ was estimated

355 to be 250 and $75 \mu \mathrm{m}$ in the $\mathrm{x}$ - and $\mathrm{y}$-directions, respectively. Table 2 shows the estimated

356 resolution from the crystals by the SDI system with pixels binned $1 \times 1$ and $4 \times 4$ at 254 and 610

$357 \mathrm{~nm}$. Overall, these data indicate that pixel binning is not the limiting factor when it comes to

358 resolution; the dimension of the light emitting slit and shadowing effects seem to be significant

359 contributing factors. 
362 The dissolution behavior of lidocaine from selected single crystals into stagnant phosphate buffer 363 has previously been investigated by UV imaging. The study showed that the dissolved lidocaine 364 seems to gather at the bottom of the quartz cell, which may be explained by the formation of a 365 density gradient as lidocaine dissolves leading to natural convection [16]. Hydrogel matrixes 366 have been shown to suppress natural convection due to density gradients [43,48-50]. In the 367 current study, the effect of introducing a $0.5 \%(\mathrm{w} / \mathrm{v})$ agarose hydrogel at $\mathrm{pH} 7.4$ as a dissolution 368 medium on the dissolution behavior of a single lidocaine crystal under stagnant conditions was 369 visualized. Fig. 8 shows the absorbance maps of the dissolution behavior of lidocaine. The image 370 resolution is not affected by introduction of the gel (Fig. 8), which is understandable in the light 371 of the discussion in section 3.1, and the crystals are still readily apparent. During dissolution of 372 lidocaine in the hydrogel matrix, the absorbance contours mapped around the crystals were 373 almost symmetrical (Fig. 8A). This contrasts with the irregular contours around the crystals in 374 the phosphate buffered solution (Fig. 8B). The symmetrical absorbance maps formed in the

375 hydrogel matrix indicate that the natural convection seen in aqueous solution has been 376 effectively suppressed in the hydrogel matrix. The mass transport of dissolved lidocaine in the 377 hydrogel is solely due to diffusion whereas transport of dissolved lidocaine the solution is due to 378 convective currents as well as diffusion. 
381 Diffusion coefficients of drug compounds in hydrogel matrixes have previously been determined 382 by fitting data to equations based on Fick's second law [21,42]. In these studies, the samples are 383 placed in a manner such that the diffusion can be assumed to occur only in the x-direction. The 384 determined diffusion coefficients are influenced by the defined position of the interface, $\mathrm{x}_{0}$ (cf.

385 Eq. 1), and the precision with which the position of the interface can be determined may 386 therefore be important for the results obtained. In our previous diffusion studies using a D100 387 imaging system [21,42], the interface between the sample and the release (acceptor) medium was 388 perpendicular to the fibre optic line source, i.e. oriented such that diffusion occur in $\mathrm{x}$-direction 389 where the imaging system has the lowest resolution. The results in section 3.1.2 showed that the 390 orientation of the objects relative to the line light source has a significant impact on the 391 resolution. Tests were therefore undertaken to check whether rotation of the output end of the 392 round-to-line fibre optic cable by $90^{\circ}$ influenced the initial appearance and sharpness of the 393 interface between a hydrogel loaded with lidocaine and a blank hydrogel. Interestingly, no 394 difference in the sharpness of the boundary between the hydrogels was observed (data not 395 shown), and the slopes of the tangent to the curves at the interface were similar at time zero. 396 However, the curves were associated with more scatter when the line source was rotated $90^{\circ}$, 397 which may be attributed to the higher resolution in this direction. By applying Eq. 1 to the 398 normalized absorbance-distance profiles (Fig. 9A), diffusion coefficients of lidocaine in the 399 hydrogel matrixes were determined. The apparent diffusion coefficients were found to decrease 400 with time (10 - $180 \mathrm{~min})$. By plotting the diffusion coefficient as a function of the reciprocal of 401 time (Fig. 9B), the apparent diffusion coefficient was obtained from the intercept of the straight 402 line with the $y$-axis $[21,51]$. The diffusion coefficient was determined to be $(6.3 \pm 0.05) \times 10^{-10}$ $403 \mathrm{~m}^{2} / \mathrm{s},(6.9 \pm 0.05) \times 10^{-10} \mathrm{~m}^{2} / \mathrm{s}$ and $(7.5 \pm 0.11) \times 10^{-10} \mathrm{~m}^{2} / \mathrm{s}(\mathrm{n}=3 \times 3)$ at $22.0 \pm 1.0^{\circ} \mathrm{C}$ using 
404 the D100, SDI and D100 system with the line rotated $90^{\circ}$, respectively. Brouneus and co-

405 workers have determined the diffusion coefficient of lidocaine hydrochloride to be $(7.49 \pm 0.43)$

$406 \times 10^{-10} \mathrm{~m}^{2} / \mathrm{s}(\mathrm{n}=8)$ in $1 \%(\mathrm{w} / \mathrm{w})$ agarose gel at $25^{\circ} \mathrm{C}$ by measuring the amount of lidocaine

407 diffusing from a well stirred solution of $25 \mathrm{mM}$ lidocaine into the gel at specified time points

408 [52]. The diffusion coefficient of lidocaine in phosphate buffered solution was determined to be

$409(5.8 \pm 0.2) \times 10^{-10} \mathrm{~m}^{2} / \mathrm{s}$ using TDA, which is in accordance with the previously determined

410 diffusion coefficient of lidocaine in buffer solution at $\mathrm{pH} 7.4\left((5.5 \pm 0.2) \times 10^{-10} \mathrm{~m}^{2} / \mathrm{s}\right)[32]$. Due

411 to the unhindered diffusion of small molecules in the agarose hydrogel matrix, the diffusion

412 coefficient of lidocaine obtained in the hydrogel was expected to be comparable to the value

413 obtained in aqueous solution. The observed variation in the obtained diffusion coefficients for

414 lidocaine in agarose gels and in solution is within the normal range, when different methods are

415 applied. Using the current UV imaging instrumentation, where the effective height in the y-

416 direction is $3.9 \mathrm{~mm}$ and the length in the $\mathrm{x}$-direction is $\sim 8 \mathrm{~mm}$ for the setup used for the

417 diffusion experiments, it is advantageous to study diffusion in the x-direction due to a longer

418 potential diffusion distance allowing the process to be followed for longer periods of time. The

419 effective imaging area in the x-direction is $7-9 \mathrm{~mm}$ in the D100 and SDI system, while it is $4-6$

$420 \mathrm{~mm}$ in the D100 system with the line of fibres rotated $90^{\circ}$ and the fall of intensity with distance

421 as noted in Fig. 2A. The reason why a difference with respect to sharpness of the interface was

422 not observed using the different UV imaging setups may be due to the immediate diffusion of

423 lidocaine as the lidocaine loaded gel is placed side by side with the blank hydrogel matrix. The

424 time for the quartz cell containing the sample to be placed under the UV imaging sensor head

425 varies between experiments and is generally in the order of 1 to $5 \mathrm{~min}$. The root-mean-square

426 distances $\left(\left\langle x^{2}\right\rangle^{1 / 2}\right)$ of lidocaine at 1 and 5 min were calculated to be 300 and $670 \mu \mathrm{m}$, 
427 respectively, using the formula for one-dimensional diffusion $\left\langle\mathrm{x}^{2}\right\rangle^{1 / 2}=\sqrt{ }(2 \times D \times t)$ and a

428 diffusion coefficient of $7.5 \times 10^{-10} \mathrm{~m}^{2} / \mathrm{s}$. These are relatively large distances, in comparison to the

429 resolution which is in the order of 20 to $200 \mu \mathrm{m}$. Thus, the experimental procedure rather than

430 instrument performance appears to be the limiting factor in these diffusion assays.

\section{4. Conclusion}

433 The present study showed that the apparent absorption coefficients depend on the spectroscopic

434 instrumentation used, highlighting the importance of investigating the linearity prior to

435 dissolution imaging. For quantitative results, the apparent molar absorption coefficient should be

436 determined using the UV imaging system rather than a conventional spectrophotometer.

437 The main difference between the D100 and SDI imaging systems is the introduction of a

438 collimating lens in the latter system. This leads to several improvements in instrument

439 performance. The SDI imaging system showed an increased uniformity of the light intensity

440 across the imaging area as well as an improved resolution, which may be explained by a reduced

441 shadowing effect. Both systems have as light source a line of $100 \mu \mathrm{m}$ fibres aligned in the $\mathrm{x}-$

442 direction, which means that resolution is greatest in the y-direction. The main parameter

443 influencing the resolution was found to be the distance of the object above the cover slip and the

444 sensor surface, consistent with the optical lever effect. Under the most favorable conditions,

445 with a grid placed directly on the cover slip, the resolution was estimated to 12.5 and $16.7 \mathrm{lp} / \mathrm{mm}$

446 in the $\mathrm{x}$ - and $\mathrm{y}$-directions, respectively. Effects related to positioning of objects should therefore

447 be taken into account during designing of experiments and image interpretation. 
448 UV imaging offers detailed insights into dissolution processes as shown for lidocaine crystals. In

449 aqueous solution, natural convection leads to dense lidocaine solution accumulating at the

450 bottom of the cell. Agarose gels are shown to be able to suppress the effect of natural convection

451 arising from density gradients, in accordance with previous studies [16]. Hydrogels may thus be

452 suitable matrixes for visualizing and characterizing dissolution (and release) processes under

453 stagnant conditions. In relation to studying diffusion processes in hydrogels, the positioning of

454 the diffusion boundary relative to the fibre optic line source (parallel versus perpendicular) did

455 not improve the sharpness of the interface even at the shortest measurement time. Calculations

456 of root-mean-square distances for diffusion showed that this could have been due to diffusion

457 occurring as the experiment was being setup, rather than the instrument limiting the sharpness of

458 the diffusion boundary.

459 The knowledge obtained in the current study about the instrument performance characteristics

460 will be helpful in the design and interpretation of UV imaging based release and dissolution

461 studies.

\section{Acknowledgements}

464 This project has received funding from the European Union's Horizon 2020 research and 465 innovation program under the Marie Sklodowska-Curie grant agreement No 644056. The authors 466 alone are responsible for the content and writing of this paper. 


\section{References}

469

470

471

472

473

474

475

476

477

478

479

480

481

482

483

484

485

486

487

488

489

490

491

492

493

494

495

496

497

498

499

[1] J. Emami, In vitro - in vivo correlation: from theory to applications, J. Pharm. Pharmc. Sci. 9 (2006) 169-189.

[2] M. Windbergs, D.A. Weitz, Drug dissolution chip (DDC): A microfuidic approach for drug release. Small 7 (2011) 3011-3015.

[3] M. Kuentz, Analytical technologies for real-time drug dissolution and precipitation testing on a small scale, J. Pharm. Pharmacol. 67 (2014) 143-159.

[4] A.V. Ewing, G.S. Clarke, S.G. Kazarian, Attenuated total reflection-Fourier transformed infrared spectroscopic imaging of pharmaceuticals in microfluidic devices, Biomicrofluidics 10 (2016) 024125.

[5] K. Mäder, G. Bacic, A. Domb, O. Elmalak, R. Langer, H.M. Swartz, Noninvasive in vivo monitoring of drug release and polymer erosion from biodegradable polymers by EPR spectroscopy and NMR imaging, J. Pharm. Sci. 86 (1997) 126-134.

[6] J.C. Richardson, R.W. Bowtell, K. Mäder, C.D. Melia, Pharmaceutical applications of magnetic resonance imaging (MRI), Adv. Drug Deliv. Rev. 57 (2005) 1191-1209.

[7] K.P. Nott, Magnetic resonance imaging of tablet dissolution, Eur. J. Pharm. Biopharm. 74 (2010) 78-83.

[8] C. Chen, L.F. Gladden, M.D. Mantle, Direct visualization of in vitro drug mobilization from lescol XL tablets using two-dimensional ${ }^{19} \mathrm{~F}$ and ${ }^{1} \mathrm{H}$ magnetic resonance imaging, Mol. Pharm. 11 (2013) 630-637.

[9] S.G. Kazarian, J. van der Weerd, Simultaneous FTIR spectroscopic imaging and visible photography to monitor tablet dissolution and drug release, Pharm. Res. 25 (2008) 853-860.

[10] J.A. Kimber, S.G. Kazarian, F. Stepanek, Microstructure-based mathematical modelling and spectroscopic imaging of tablet dissolution, Comput. Chem. Eng. 35 (2011) 1328-1339.

[11] S.G. Kazarian, A.V. Ewing, Applications of Fourier transform infrared spectroscopic imaging to tablet dissolution and drug release, Expert Opin. Drug Deliv. 10 (2013) 12071221.

[12] M. Windbergs, M. Jurna, H.L. Offerhaus, J.L. Herek, P. Kleinebudde, C.J. Strachan, Chemical imaging of oral solid dosage forms and changes upon dissolution using coherent anti-stokes Raman scattering microscopy, Anal. Chem. 81 (2009) 2085-2091.

[13] G.S. Bajwa, K. Hoebler, C. Sammon, P. Timmins, C.D. Melia, Microstructural imaging of early gel layer formation in HPMC matrices, J. Pharm. Sci. 95 (2006) 2145-2157. 
[14] F. Brandl, F. Kastner, R.M. Gschwind, T. Blunk, J. Tessmar, A. Göpferich, Hydrogel-based drug delivery systems: Comparison og drug diffusivity and release kinetics, J. Control. Release 142 (2010) 221-228.

[15] J.P. Boetker, M. Savolainen, V. Koradia, F. Tian, T. Rades, A. Müllertz, C. Cornett, J. Rantanen, J. Østergaard, Insights into the early dissolution events of amlodipine using UV imaging and Raman spectroscopy, Mol. Pharm. 8 (2011) 1372-1380.

[16] J. Østergaard, F. Ye, J. Rantanen, A. Yaghmur, S.W. Larsen, C. Larsen, H. Jensen, Monitoring lidocaine single-crystal dissolution by ultraviolet imaging, J. Pharm. Sci. 100 (2011) 3405-3410.

[17] W.L. Hulse, J. Gray, R.T. Forbes, A discriminatory intrinsic dissolution study using UV area imaging analysis to gain additional insights into the dissolution behaviour of active pharmaceutical ingredients, Int. J. Pharm. 434 (2012) 133-139.

[18] M. Li, N. Qiao, K. Wang, Influence of sodium lauryl sulfate and tween 80 on carbamazepinenicotinamide cocrystal solubility and dissolution behaviour, Pharmaceutics 5 (2013) 508524.

[19] N. Qiao, K. Wang, W. Schlindwein, A. Davies, M. Li, In situ monitoring of carbamazepinenicotinamide cocrystal intrinsic dissolution behaviour, Eur. J. Pharm. Biopharm. 83 (2013) $415-426$.

[20] J. Østergaard, J. Lenke, S.S. Jensen, Y. Sun, Y. Fengbin, UV imaging for in vitro dissolution and release studies: Initial experiences, Dissolut. Technol. 22 (2014) 27-38.

[21] F. Ye, A. Yaghmur, H. Jensen, S.W. Larsen, C. Larsen, J. Østergaard, Real-time UV imaging of drug diffusion and release from Pluronic F127 hydrogels, Eur. J. Pharm. Sci. 43 (2011) 236-243.

[22] J. Østergaard, E. Meng-Lund, S.W. Larsen, C. Larsen, K. Petersson, J. Lenke, H. Jensen, Real-time UV imaging of nicotine release from transdermal patch, Pharm. Res. 27 (2010) 2614-2623.

[23] J. Østergaard, J.X. Wu, K. Naelapaa, J.P. Boetker, H. Jensen, J. Rantanen, Simultaneous UV imaging and raman spectroscopy for the measurement of solvent-mediated phase transformations during dissolution testing, J. Pharm. Sci. 103 (2014) 1149-1156.

[24] F. Ye, S.W. Larsen, A. Yaghmur, H. Jensen, C. Larsen, J. Østergaard, Drug release into hydrogel-based subcutaneous surrogates studied by UV imaging, J. Pharm. Biomed. Anal. 71 (2012) 27-34.

[25] Y. Lu, L. Mingzhong, Simultaneous rapid determination of the solubility and diffusion coefficients of poorly water-soluble drug based on a novel UV imaging system, J. Pharm. Sci. 105 (2016) 131-138. 
[26] N. Gautschi, P.V. Hoogevest, M. Kuentz, Amorphous drug dispersions with mono- and diacyl lecithin: On molecular categorization of their feasibility and UV dissolution imaging, Int. J. Pharm. 491 (2015) 218-230.

[27] S.S. Jensen, H. Jensen, E.H. Møller, C. Cornett, F. Siepmann, J. Siepmann, In vitro release studies of insulin from lipid implants in solution and in a hydrogel matrix mimicking the subcutis, Eur. J. Pharm. Sci. 81 (2016) 103-112.

[28] F. Oukacine, L. Garrelly, B. Romestand, D.M. Goodall, T. Zou, H. Cottet, Focusing and mobilization of bacteria in capillary electrophoresis, Anal. Chem. 83 (2011) 1571-1578.

[29] P.L. Urban, D.M. Goodall, E.T. Bergström, N.C. Bruce, Electrophoretically mediated microanalysis of a nicotinamide adenine dinucleotide-dependent enzyme and its facile multiplexing using an active pixel sensor UV detector, J. Chromatogr. A 1162 (2007) 132140 .

[30] ISO 12233:2014(en) Photography - Electronic still picture imaging - Resolution and spatial frequency responses. International Organization for Standardization, Geneva, Switzerland. https://www.iso.org/obp/ui/\#iso:std:iso:12233:ed-2:v1:en. 2015 (Accessed 25-06-2015).

[31] J. Crank The mathematics of diffusion, Oxford University Press, Oxford, 1975.

[32] F. Ye, H. Jensen, S.W. Larsen, A. Yaghmur, C. Larsen, J. Østergaard, Measurement of drug diffusivities in pharmaceutical solvents using Taylor dispersion analysis, J. Pharm. Biomed. Anal. 61 (20112012) 176-183.

[33] M. Kulp, P.L. Urban, M. Kaljurand, E.T. Bergström, D.M. Goodall, Visualization of electrophoretically mediated in-capillary reactions using a complementary metal oxide semiconductor-based absorbance detector, Anal. Chim. Acta 570 (2006) 1-7.

[34] P.L. Urban, D.M. Goodall, E.T. Bergstrom, N.C. Bruce, Electrophoretic assay for penicillinase: Substrate specificity screening by parallel CE with an active pixel sensor, Electrophoresis 28 (2007) 1926-1936.

[35] P.L. Urban, D.M. Goodall, A.Z. Carvalho, E.T. Bergström, A. Van Schepdael, N.C. Bruce, Multi-compound electrophoretic assays for tyramine oxidase with a UV area detector imaging multiple windows on a looped capillary, J. Chromatogr. A 1206 (2008) 52-63.

[36] J. Østergaard, H. Jensen, Simultaneous evaluation of ligand binding properties and protein size by electrophoresis and Taylor dispersion in capillaries, Anal. Chem. 81 (2009) 86448648.

[37] S. Chatterjee, V. Shanker, P.K. Ghosh, Trapping parameters and kinetics in $\mathrm{Gd}_{2} \mathrm{O}_{2} \mathrm{~S}: \mathrm{Tb}$ phosphor, Solid state Commun. 80 (1991) 877-880.

[38] M.M. Blouke, M.W. Cowens, J.E. Hall, J.A. Westphal, A.B. Christensen, Ultraviolet downconverting phosphor for use with silicon CCD imagers, Appl. Opt. 19 (1980) 33183321. 
[39] M.W. Cowens, M.M. Blouke, T. Fairchild, J.A. Westphal, Coronene and liumogen as VUV sensitive coatings for Si CCD imagers: a comparison, Appl. Opt. 19 (1980) 3727-3728.

[40] J.P. Boetker, J. Rantanen, T. Rades, A. Müllertz, J. Østergaard, H. Jensen, A new approach to dissolution testing by UV imaging and finite element simulations, Pharm. Res. 30 (2013) 1328-1337.

[41] J. Østergaard, E. Meng-Lund, S. Larsen, C. Larsen, K. Petersson, J. Lenke, H. Jensen, RealTime UV imaging of nicotine release from transdermal patch, Pharm. Res. 27 (2010) 26142623.

[42] S.S. Jensen, H. Jensen, C. Cornett, E.H. Møller, J. Østergaard, Insulin diffusion and selfassociation characterized by real-time UV imaging and Taylor dispersion analysis, J. Pharm. Biomed. Anal. 92 (2014) 203-210.

[43] M.H. Gaunø, T. Vilhelmsen, C.C. Larsen, J.P. Boetker, J. Wittendorff, J. Rantanen, J. Østergaard, Real-time in vitro dissolution of 5-aminosalicylic acid from single ethyl cellulose coated extrudates studied by UV imaging, J. Pharm. Biomed. Anal. 83 (2013) 4956.

[44] S. Görög Ultraviolet-visible spectrophotometry in pharmaceutical analysis, CRC Press, Boca Raton, 1995.

[45] L. Sommer Analytical absorption spectrophotometry in the visible and ultraviolet: The principles, Elsevier Science Publishers, Amsterdam, 1989.

[46] D.S. Hage, J.D. Carr Analytical chemistry and quantitative analysis, Prentice Hall, Boston, 2011.

[47] K.L. Chan, S.G. Kazarian, New opportunities in micro- and macro-attenuated total reflection infrared spectroscopic imaging: spatial resolution and sampling versatility, Appl. Spectrosc. 57 (2003) 381-389.

[48] S.S. Jensen, H. Jensen, C. Cornett, E.H. Møller, J. Østergaard, Real-time UV imaging identifies the role of $\mathrm{pH}$ in insulin dissolution behavior in hydrogel-based subcutaneous tissue surrogate, Eur. J. Pharm. Sci. 69 (2015) 26-36.

[49] B. Lorber, C. Sauter, A. Theobald-Dietrich, A. Moreno, P. Schellenberger, M.C. Robert, B. Capelle, S. Sanglier, N. Potier, R. Giege, Crystal growth of proteins, nucleic acids, and viruses in gels, Prog. Biophys. Mol. Biol. 101 (2009) 13-25.

[50] J.M. Garcia-Ruiz, M.L. Novella, R. Moreno, J.A. Gavira, Agarose as crystallization media for proteins I: transport processes, J. Cryst. Growth 232 (2001) 165-172.

[51] V.F. Felicetta, A.E. Markham, Q.P. Peniston, J.L. McCarthy, A study of diffusion in agar gels by a light absorption method, J. Am. Chem. Soc. 71 (1949) 2879-2885. 
606

607

608
[52] F. Brouneus, K. Karami, P. Beronius, L.O. Sundelöf, Diffusive transport properties of some local anesthetics applicable for iontophoretic formulation of the drugs, Int. J. Pharm. 218 (2001) 57-62. 

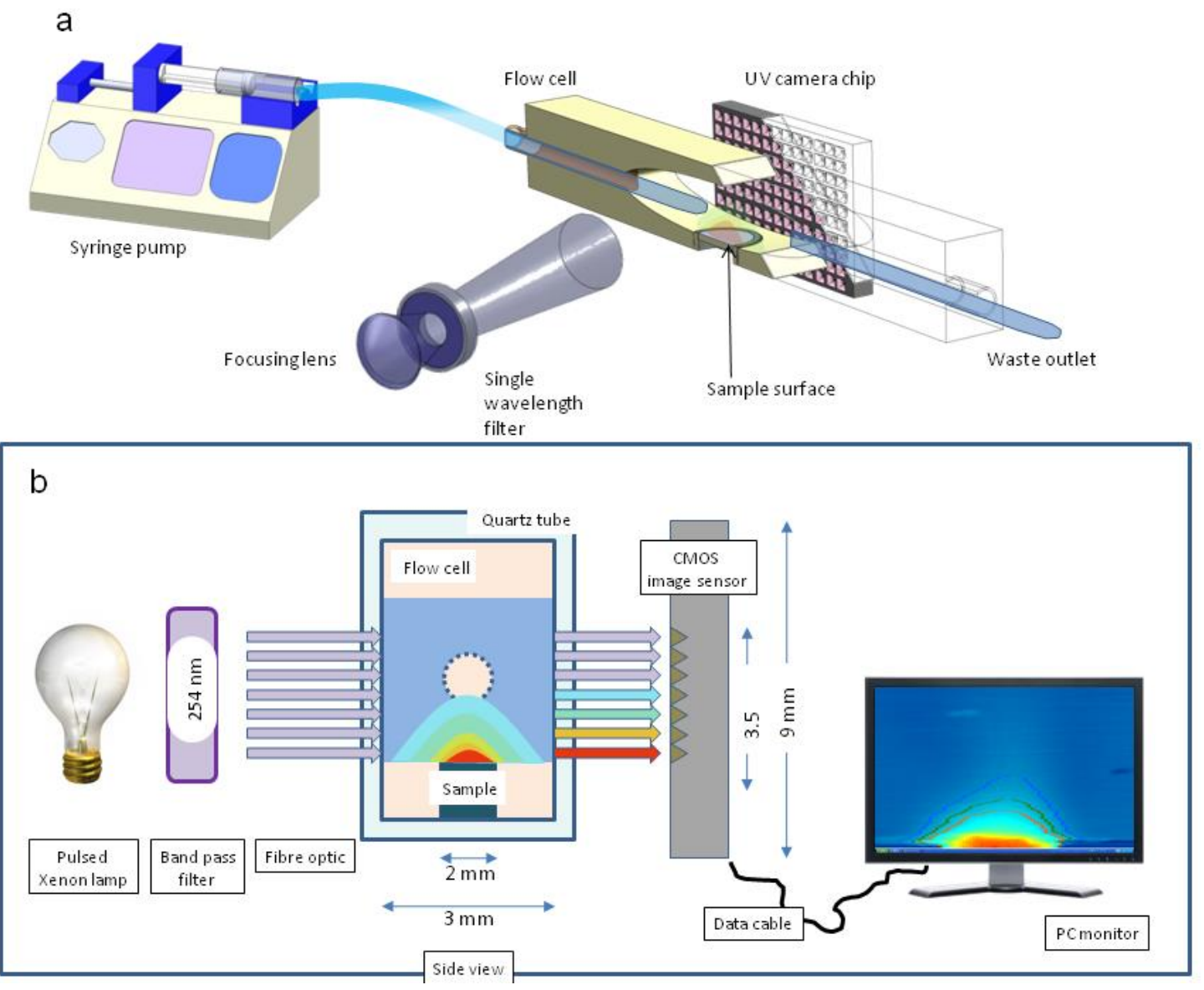

611 Fig. 1. Schematic representation of the UV imaging setup (reprinted from [22] with permission

612 from Springer). 


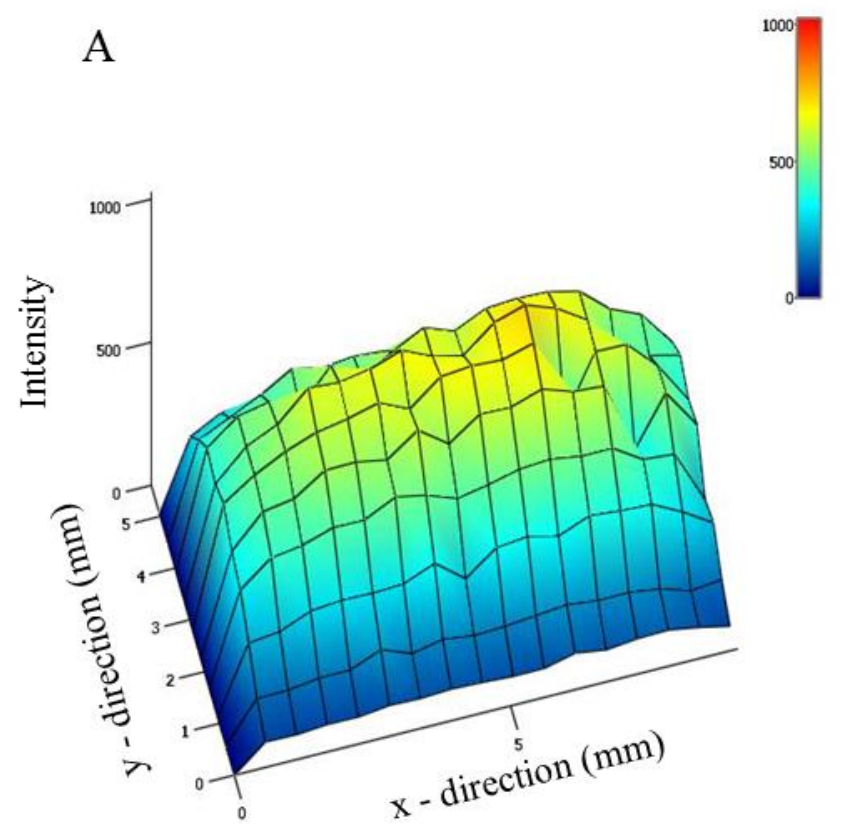

613

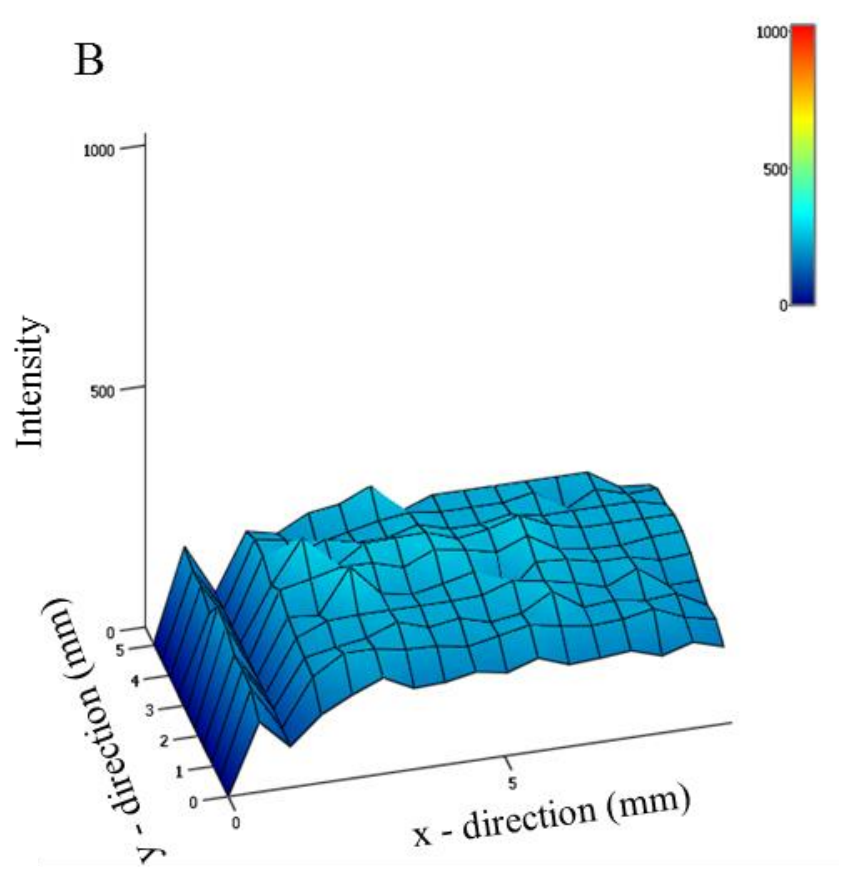

614 Fig. 2. Light intensity maps of the imaging area in the $x$ - and y-direction of the A) ActiPix D100

615 UV area imaging system (Paraytec Ltd, York, UK) and B) Sirius SDI (Sirius Analytical Ltd, East

616 Sussex, UK) imaging system with pixels binned $1 \times 1$ at $254 \mathrm{~nm}$. 
A

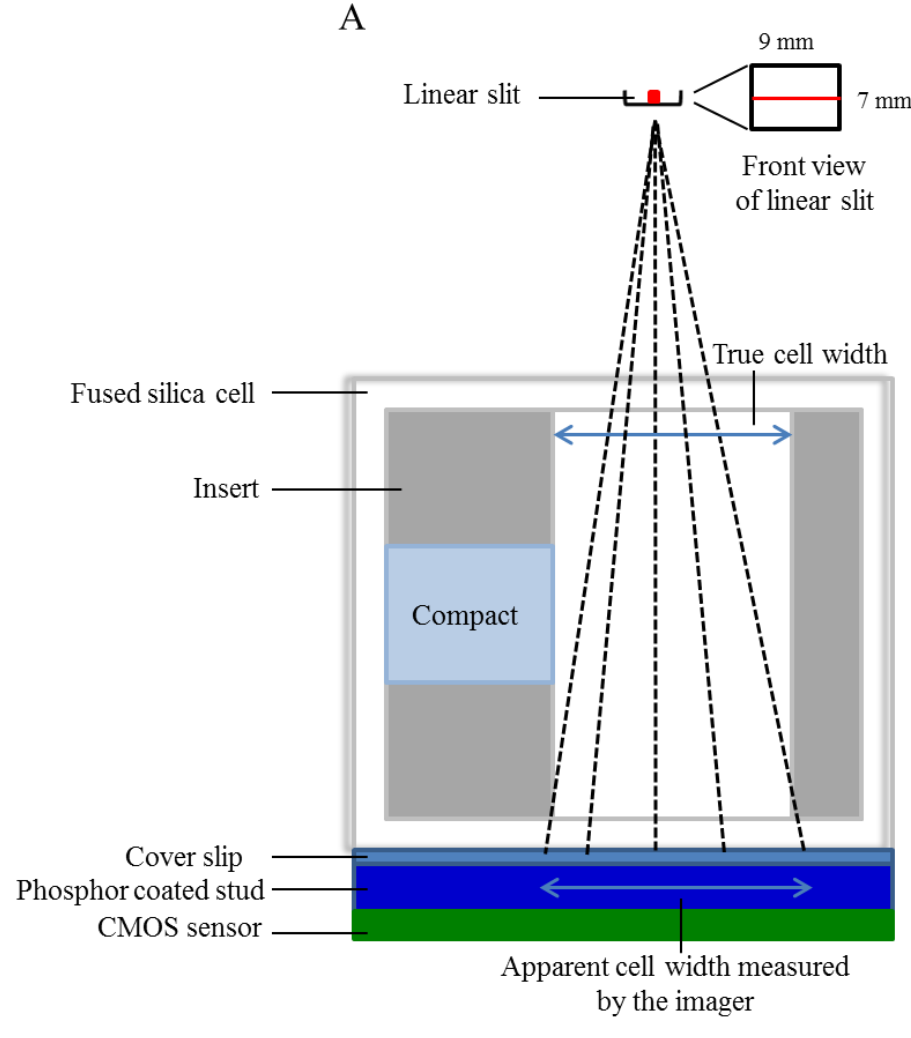

$\mathrm{B}$

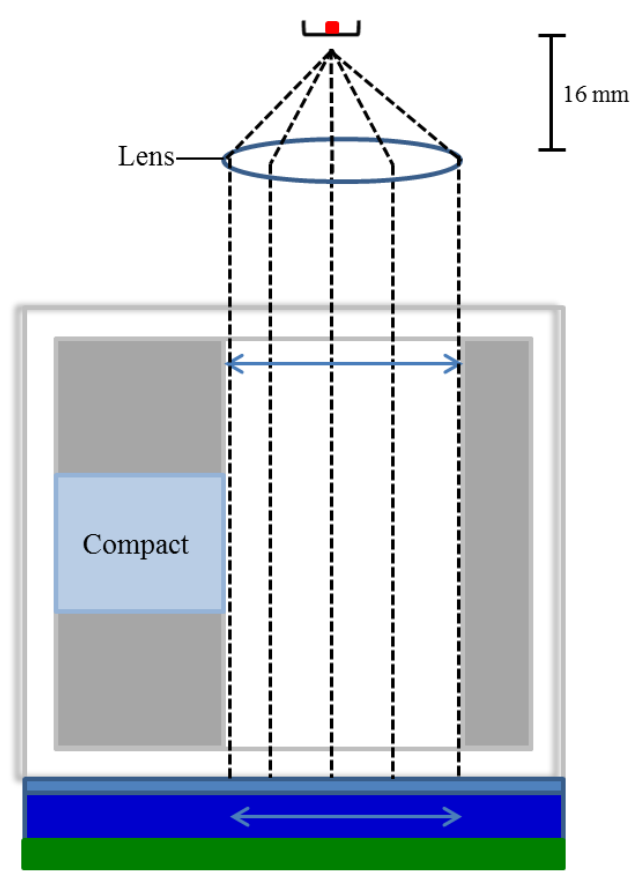

Fig. 3. Schematic illustration of sensor head components and light paths for the D100 (A) and

619 SDI (B) imaging systems. The drawings are not to scale, and the linear slit height is $16 \mathrm{~mm}$

620 above the cylinder lens. Note the change in sensor head orientation relative to Fig. 1. 


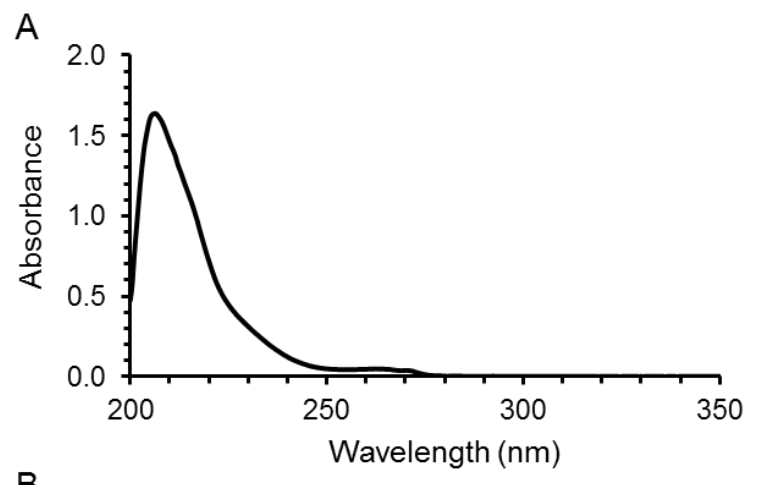

B

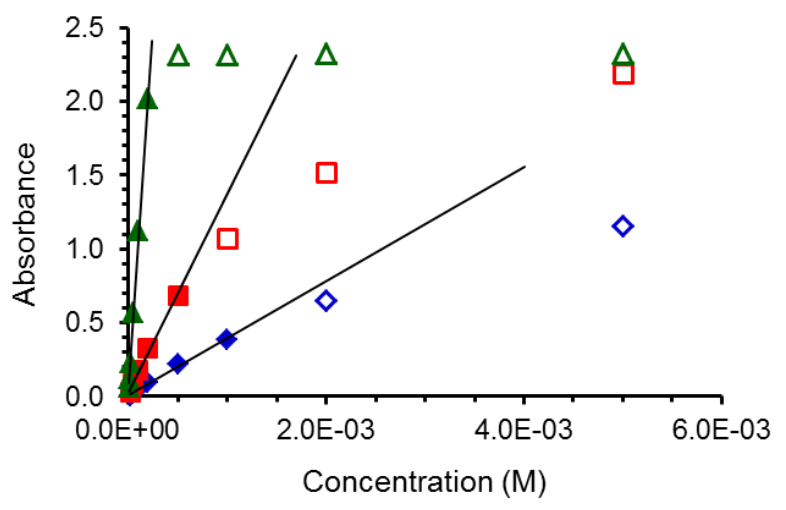

C

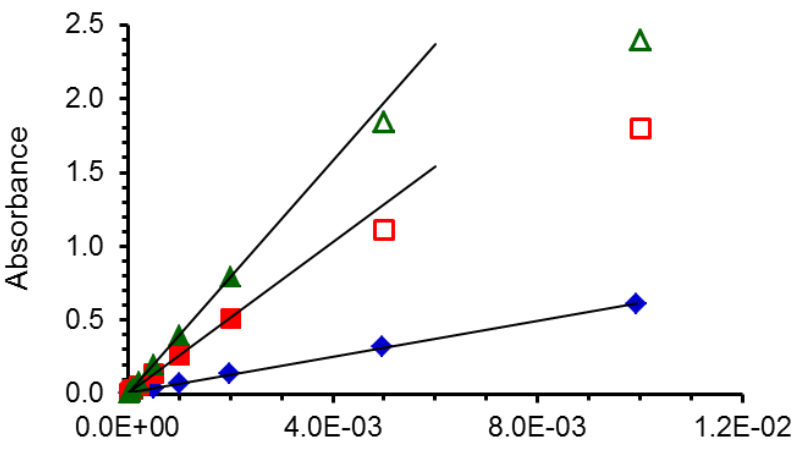

Concentration (M)

622 Fig. 4. A) UV scan of $1.0 \times 10^{-4} \mathrm{M}$ lidocaine in $0.067 \mathrm{M}$ phosphate buffered solution, $\mathrm{pH} 7.4$,

623 obtained using a conventional spectrophotometer. Calibration curves of lidocaine in phosphate

624 buffered solution at pH 7.4 obtained in quartz cells with a light path of $1(\diamond, \diamond)$ and $4 \mathrm{~mm}(\square, \square)$

625 using the SDI UV imaging and $10 \mathrm{~mm}(\boldsymbol{\Delta}, \Delta)$ by a conventional spectrophotometer at B) 214

626 and C) $254 \mathrm{~nm}$. The lines are the linear regression using only the closed symbols, and the open

627 symbols represent the points that are deviating from linearity. 


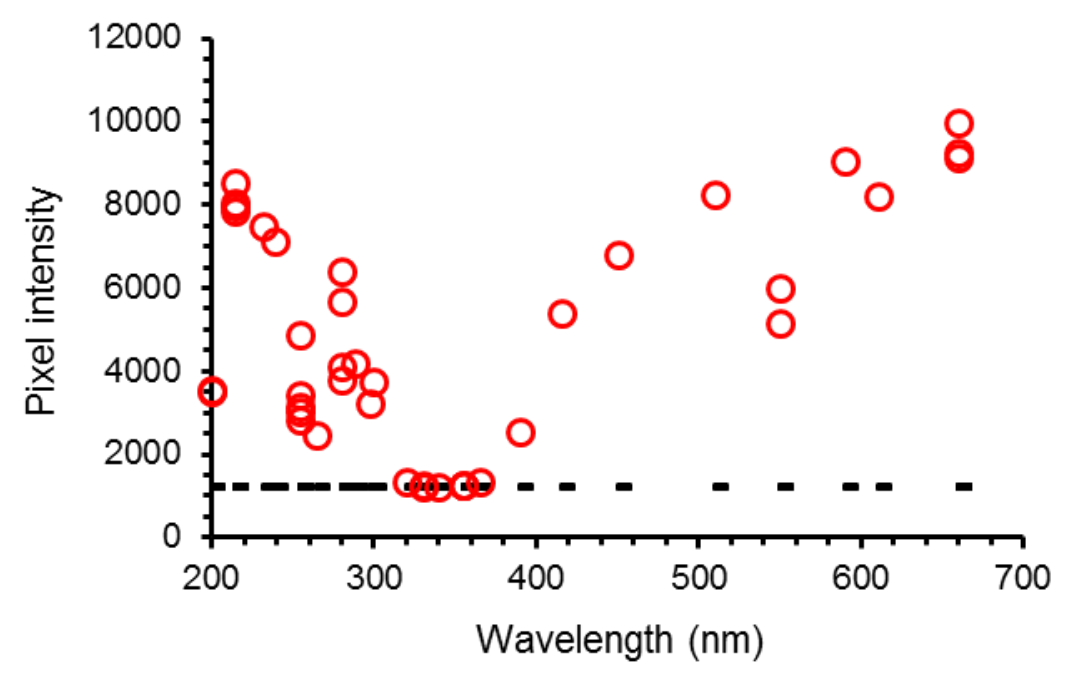

629 Fig. 5. Pixel intensities as a function of wavelength for the interference band-pass filters using the 630 SDI UV imaging instrument (०), and the measured intensities (the dark current), when the lamp 631 was turned off (-). The pixel intensities plotted were average values read from a selected image 632 area $\left(5.60 \times 4.76 \mathrm{~mm}^{2}\right)$. At some wavelengths, the pixel intensity was measured by several filters, 633 some of which had different transmission efficiency. All filters were measured on the same system 634 in a single experimental session. 

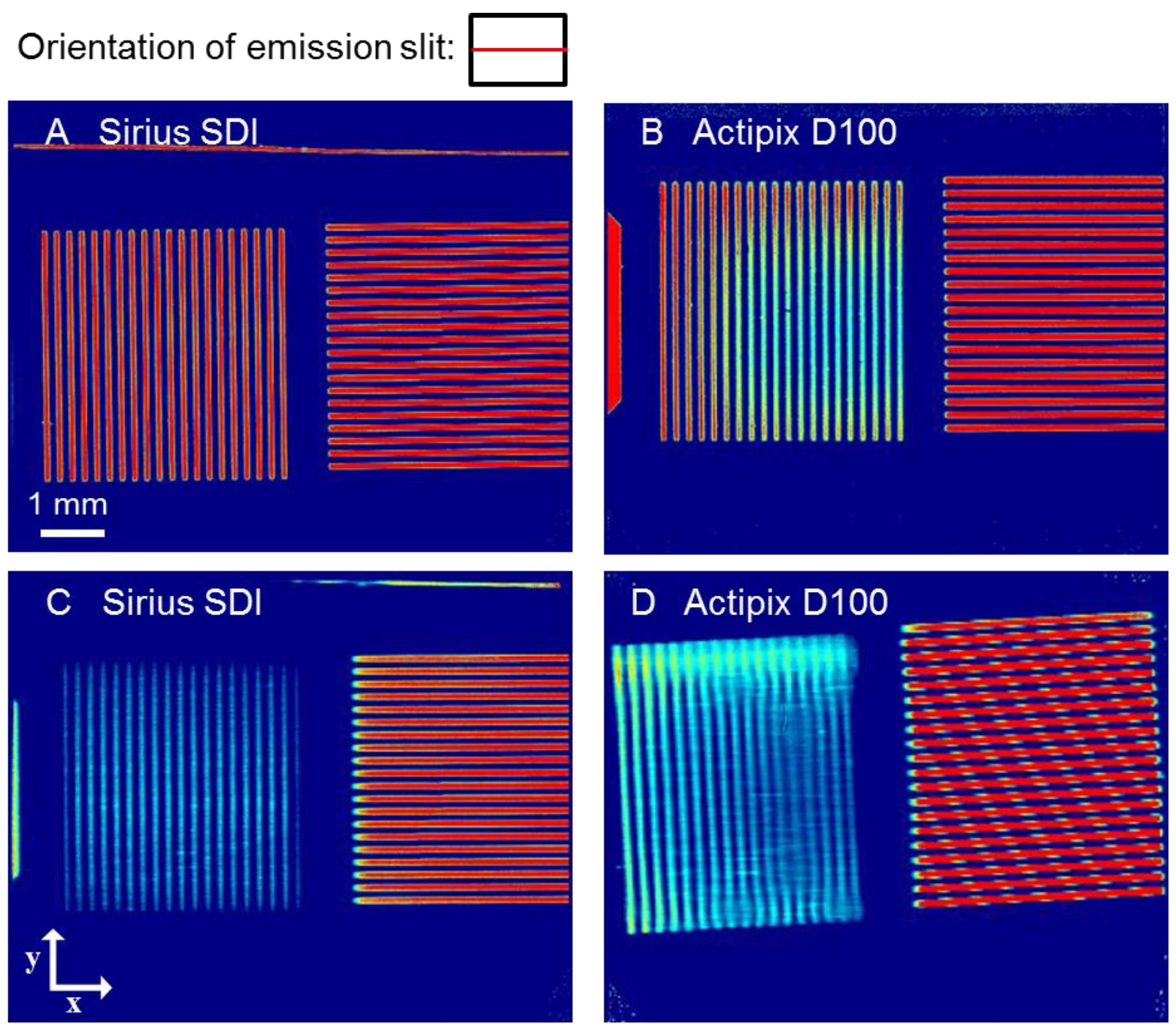

636 Fig. 6. Absorbance maps of the grids obtained by the ActiPix D100 UV Area Imaging (Paraytec

637 Ltd, York, UK) and Sirius SDI (Sirius Analytical Ltd, East Sussex, UK) imaging system with

638 pixels binned $1 \times 1$ at $610 \mathrm{~nm}$, when the bar pattern grids $(100 \mu \mathrm{m}$ line width, $100 \mu \mathrm{m}$ vacancy

639 before repeat) were placed on the cover slip of the sensor surface (A and B) and on quartz cells,

640 placing the grid $1.2 \mathrm{~mm}$ above the cover slip of the sensor surface (C and D). Images are $9.0 \times$

$6417.2 \mathrm{~mm}^{2}$ and the absorbance values range between $0 \mathrm{mAU}$ (dark blue) and 1400 mAU (red). 

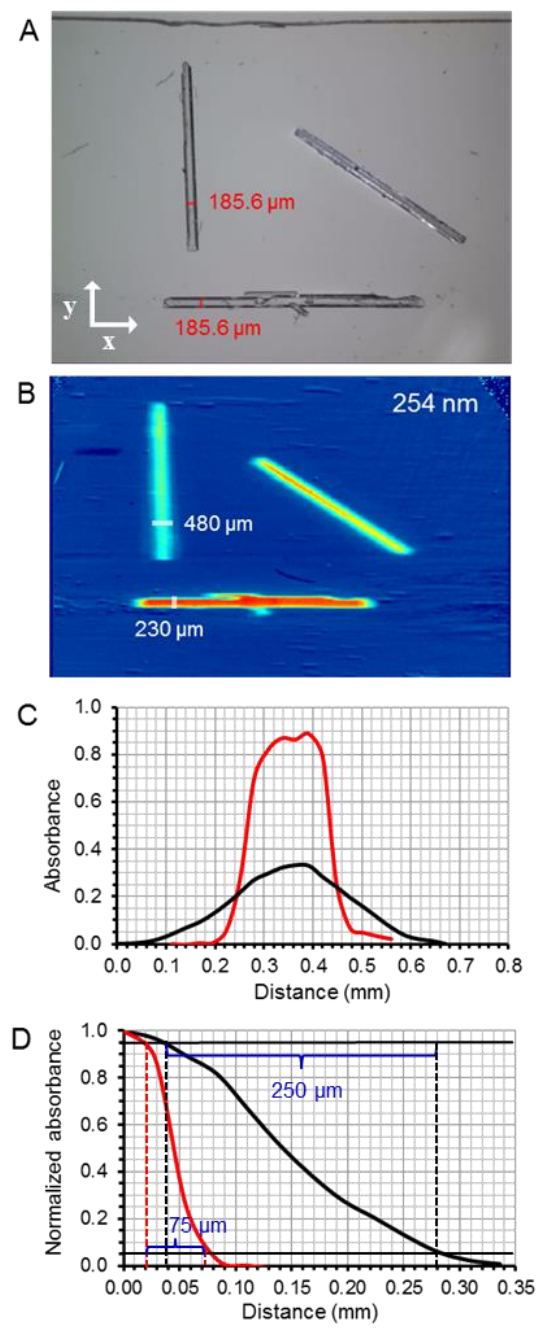

643 Fig. 7. A) Microscope photograph (the image is $8.3 \times 6.4 \mathrm{~mm}^{2}$ ) and B) absorbance maps of the

644 lidocaine crystals arranged in a quartz cell obtained by the Sirius SDI imaging system with pixels 645 binned $4 \times 4$ at $254 \mathrm{~nm}$. The image is $10.4 \times 4.6 \mathrm{~mm}^{2}$. C) Absorbance $-\mathrm{y}$-distance profile of the 646 lidocaine crystal placed in the $\mathrm{x}$-direction $(-)$ and absorbance $-\mathrm{x}$-distance profile for crystal

647 placed in the y-direction (-) for determining the width of the crystals from the absorbance maps 648 and D) normalized absorbance - distance profile of one side of a lidocaine crystal placed in the x649 direction (-) and y-direction (-) for estimating the resolution of the Sirius SDI imaging 650 system. 

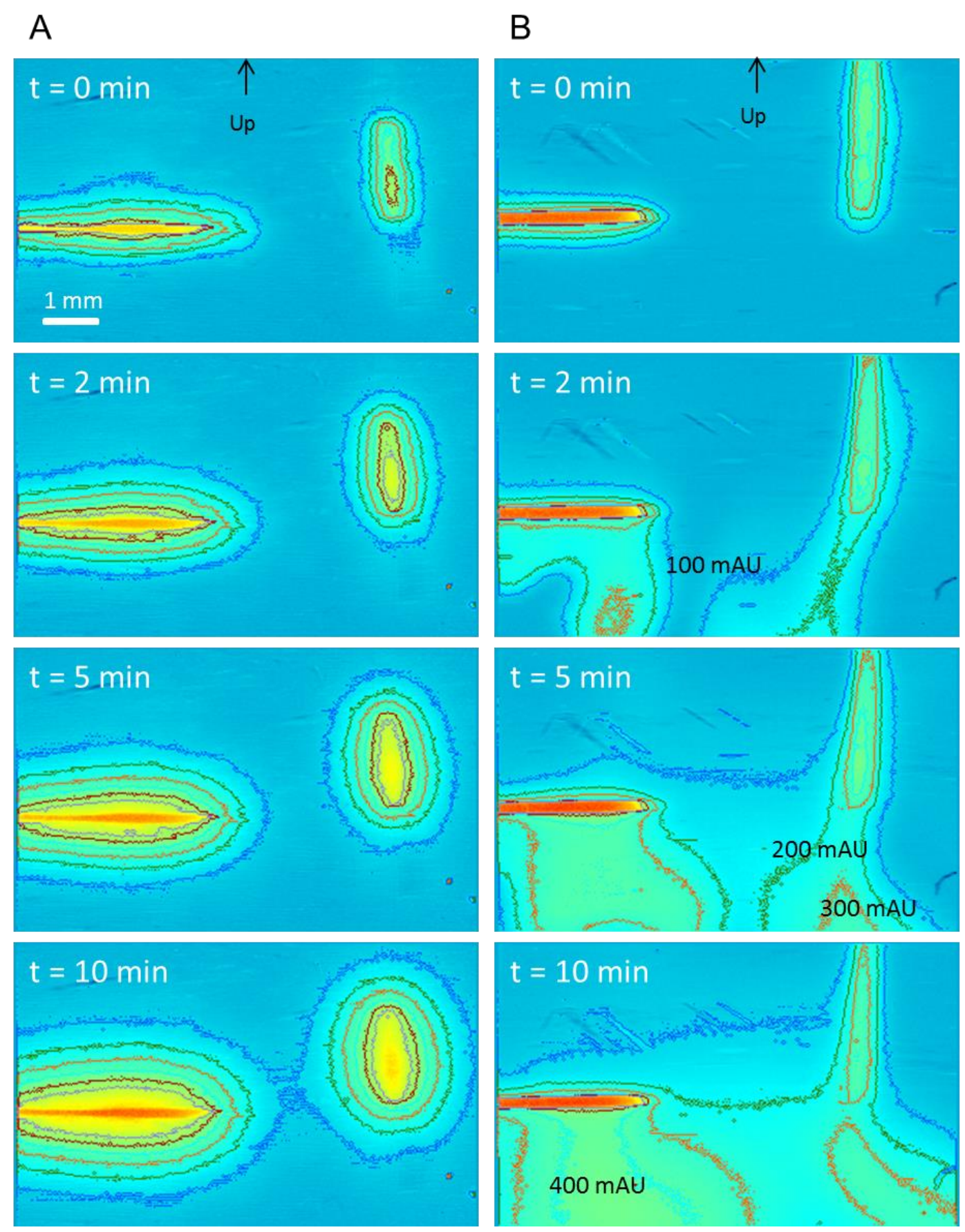

652 Fig. 8. Time-dependent absorbance contour maps of the dissolution of lidocaine crystals in A)

$6530.5 \%(\mathrm{w} / \mathrm{v})$ agarose gel, $\mathrm{pH} 7.4$ and B) $0.067 \mathrm{M}$ phosphate buffered solution, $\mathrm{pH}$ 7.4. The

654 dissolution was performed in quartz cells with $1 \mathrm{~mm}$ light path using the Sirius SDI UV imaging

655 system with the pixels binned $4 \times 4$ at $254 \mathrm{~nm}$ and the sensor head placed in the upright position. 

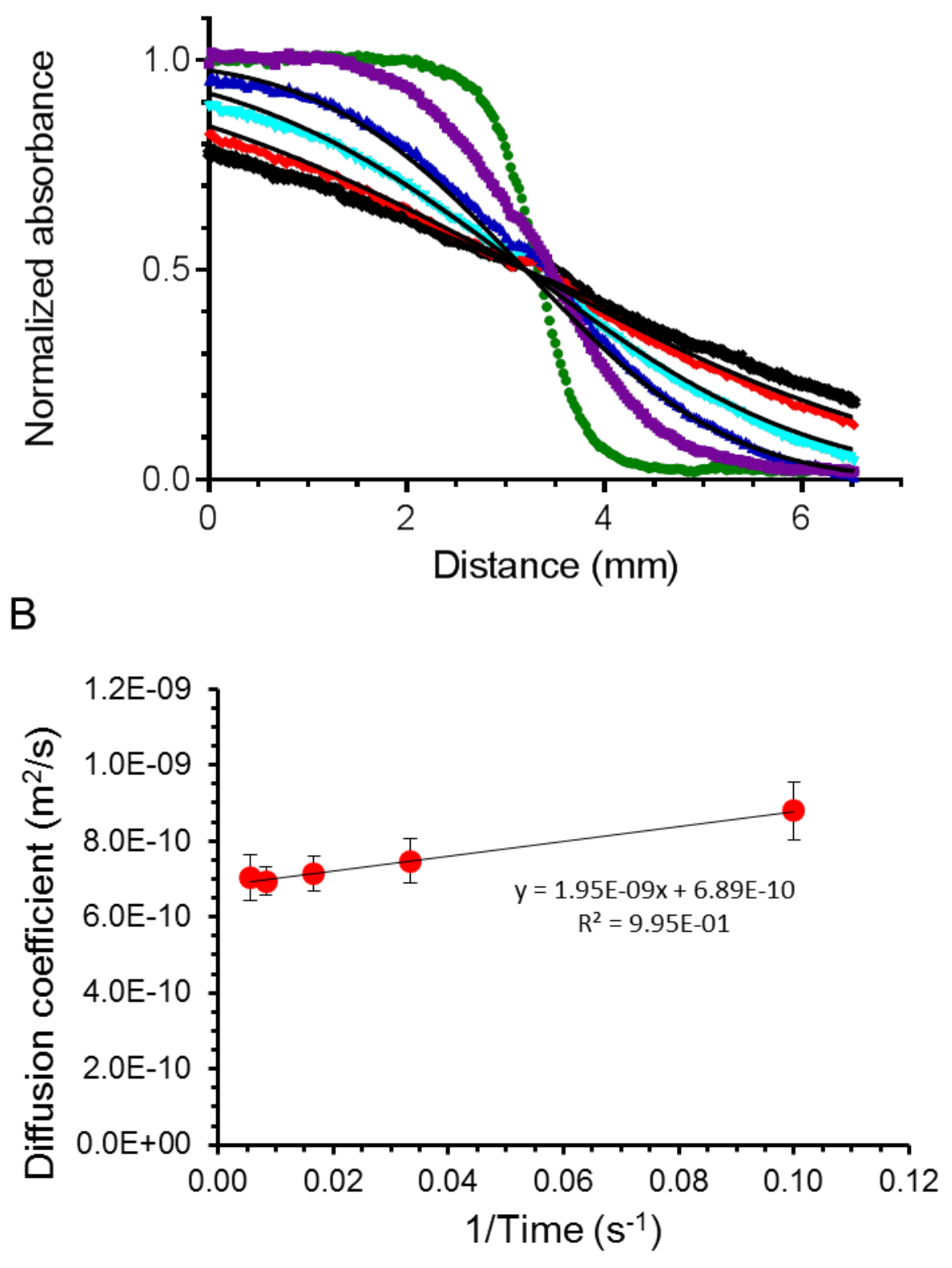

656

657 Fig. 9. A) Absorbance - distance profiles for lidocaine diffusion in $0.5 \%(w / v)$ agarose hydrogel 658 matrix, pH 7.4, after $0(\bullet), 10(\bullet), 30(\Delta), 60(\nabla), 120(\diamond)$ and $180 \mathrm{~min}(+)$ obtained using the 659 Sirius SDI system. The black lines represent the fits to Eq. (1). B) Fitted diffusion coefficients of 660 lidocaine in $0.5 \%(\mathrm{w} / \mathrm{v})$ agarose hydrogel matrix, $\mathrm{pH} 7.4$, as a function of the inverse of time. 